\title{
AL-A'RAF
}

\section{PEMBAKUAN MUSHAF UTHMANI}

\author{
Muhammad Najib \\ STAI Al-Anwar, Sarang
}

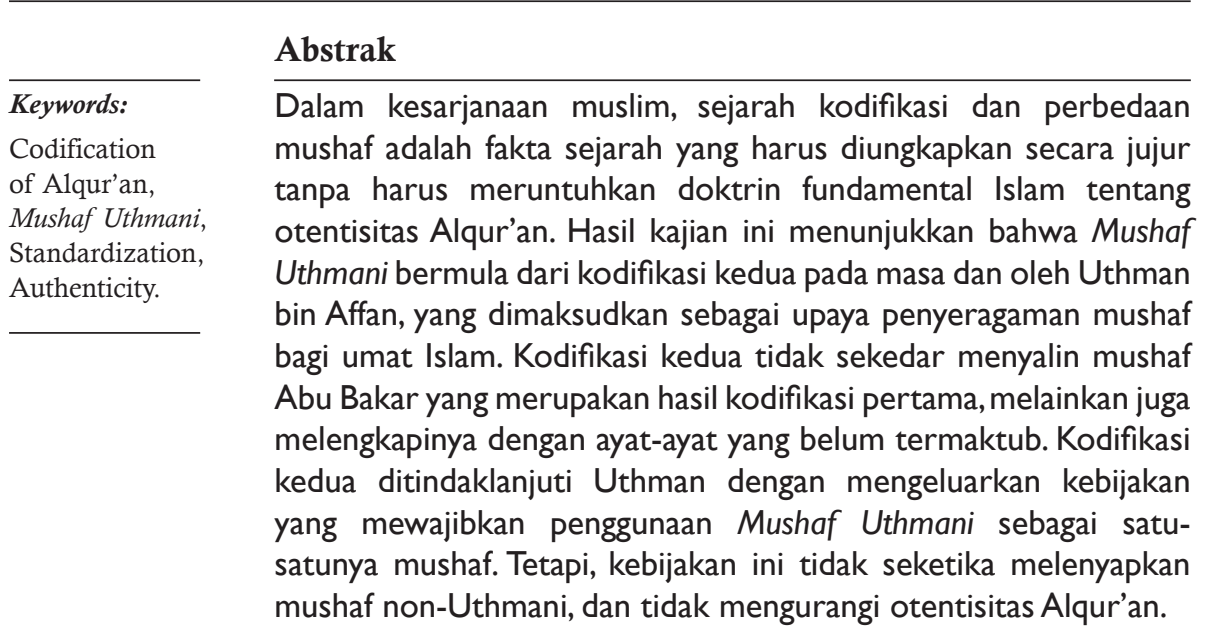

\begin{abstract}
In the Muslim's Scholar, codification's history and difference of mushaf is a historical fact which must be honestly revealed without having any purpose to demolish fundamental doctrine of Islam on the qur'anic authenticities. This study revealed that Mushaf Uthmani began from the second codification at the period of and by Uthman ibn Affan, meant as an effort to the uniformity of mushaf among Muslim communities. The second codification did not simply copy Abu Bakar's mushaf which was represented as the result of the first codification, but also completing it with the sentences which are not yet recorded. The second codification was followed up by Uthman by releasing policy which obliged the use of mushaf Uthmani as single mushaf. However, this policy did not at once wipe out non-Uthmani's mushaf, and did not lessen Qur'anic authenticities.
\end{abstract}




\section{Pendahuluan}

Salah satu aspek kajian Alqur'an yang paling mendapat perhatian dan menimbulkan banyak kontroversi adalah sejarah kodifikasi Alqur'an dan pembakuan Mushaf Uthmānì. Sudah sejak abad ke-2 H., kajian sejarah Alqur'an menjadi perhatian ulama Islam. Mereka melakukan kajian tentang perbedaan mushaf yang beredar di beberapa wilayah Islam. Ibnu Amir dengan Ikhtilāf Mașāhif al-Shām wa al-Hijā̃ wa al-Irāq, al-Kisā iy dengan Ikbtilāf Mașāhif Ablu al-Madinah wa Ablu al-Küfah wa Ablu al-Bașrah, Khalaf bin Hisyam dengan Ikbtilāf alMașạhif, dan Ibnu Abi Dawud alSijistāny dengan al-Mașāhifadalah beberapa contoh kajian sejarah Alqur'an yang dilakukan ulama Islam. Karya Ibnu Abi Dawud inilah yang kemudian menjadi rujukan utama dalam kajian-kajian sejarah Alqur'an, termasuk oleh kalangan orientalis.

Dari kalangan orientalis Barat, terdapat nama Theodore Noldeke yang menulis The History of the Qur'an. Kerja intelektual Noldeke dilanjutkan penerusnya, Friedrich Schwally, Gotthelf Bergsträsser, dan Otto Pretzl yang menyempurnakan buku tersebut menjadi 3 Jilid. Richard Bell, orientalis Inggris, dan Regis Blochere, orientalis Perancis, mengikuti jejak metodologis Noldeke dalam mengkaji Alqur'an. Bell menulis The Qur'an, dan Blochere menghasilkan karya Le Coran. Dari Australia, muncul nama Arthur Jeffery yang memberikan pengantar pada kitab al-Mașạhif karya Ibnu Abi Dawud al-Sijistany.

Sejarah Alqur'an tetap menjadi salah satu kajian terpenting di kalangan sarjana muslim kontemporer. Tiga karya terdahulu yang menjadi rujukan utama dalam kajian ini adalah al-Mașạhif Ibnu Abi Daud, The History of the Qur'an Theodore Noldeke, dan pengantar Arthur Jeffery pada al-Mașāhif. Ada dua kecenderungan dalam kajian sejarah Alqur'an di kalangan sarjana muslim kontemporer. Pertama, kajian yang cenderung mempertahankan teori dogmatis tentang sejarah Alqur'an. 
Kedua, kajian yang cenderung membongkar kemapanan sejarah Alqur'an. Kecenderungan pertama direpresentasikan oleh beberapa nama, seperti Abd al-Ṣobūr Shāhīn, Ibrahim al-Abyāry, dan Muhibbuddin Abd al-Sajjān. Sedangkan kecenderungan kedua diwakili nama-nama seperti Arkoun, Abid al-Jabiry, Sahrur, Asymawy, dan Nasr Hamid Abu Zaid.

Sejatinya, kajian tentang sejarah Alqur'an sangat sensitif karena berkaitan dengan keyakinan umat Islam paling fundamental. Setidaknya terdapat dua titik sensitif dalam kajian sejarah Alqur'an, yaitu proses kodifikasi dan adanya perbedaan mushaf yang digunakan para Sahabat. Tulisan ini akan mengkaji sejarah kodifikasi Alqur'an: dimulai dari masa pewahyuan hingga terbakukannya Mushaf Uthmani sebagai satu-satunya mushaf yang diterima oleh umat Islam.

\section{Pewahyuan Alqur'an kepada Rasulullah SAW}

Di dalam Alqur'an sendiri ditemukan beberapa ayat yang mengambarkan bagaimana Alqur'an diturunkan. Ayat-ayat tersebut dapat diklasifikasikan menjadi dua: pertama, ayat-ayat yang mengindikasikan bahwa Alqur'an diturunkan sekaligus, yaitu: al-Baqarah: 185, “...bulan Ramadhan, bulan yang di dalamnya diturunkan (permulaan) Alqur'an sebagai petunjuk bagi manusia...", al-Dukhān: 3, "Sesungguhnya kami menurunkannya pada suatu malam yang diberkahi..." dan al-Qadr: 1, "Sesungguhnya kami telah menurunkannya pada malam kemuliaan"

Kedua, ayat-ayat yang mengindikasikan bahwa Alqur'an diturunkan secara bertahap, yaitu al-Isrā': 106, “Dan Alqur'an itu telah kami turunkan dengan berangsur-angsur agar kamu membacakannya perlahan-lahan kepada manusia..." dan al-Furqān: 32, "Berkatalah orang-orang yang kafir: 'Mengapa Alqur'an itu tidak diturunkan kepadanya sekali turun saja?’ Demikianlah supaya kami perkuat hatimu dengannya dan kami membacanya secara teratur dan benar".

Gugatan orang-orang kafir dalam al-Dukhān: 32 menunjukkan bahwa yang mereka ketahui, Alqur'an diturunkan secara bertahap. Fakta 
yang disaksikan para sahabat pun demikian. Ibnu Kathīr, menuturkan bahwa 'Atiyyah bin al-Aswad merasa gamang tentang makna firman Allah pada al-Baqarah: 185 dan al-Qadr: 1, yang keduanya mengindikasikan bahwa Alqur'an diturunkan sekaligus. Padahal seperti ia ketahui, Alqur'an diturunkan pada bulan Syawal, Dzul Qa'dah, Dzul Hijjah, Muharram, Safar, Rabiul Awwal, dan Rabiuts Sani. Ibnu Abbas menjawab bahwa Alqur'an diturunkan sekaligus pada bulan Ramadan atau yang disebut malam lailatul qadar atau malam yang diberkahi. Kemudian Al-quran diturunkan secara bertahap pada bulan-bulan dan hari-hari seperti mereka saksikan ${ }^{1}$.

Jawaban Ibnu Abbas mengurai kerumitan yang menyelubungi dua kelompok ayat yang terkesan kontradiktif. Kelompok pertama menggambarkan turunya Alqur'an secara utuh dan sekaligus, sedangkan kelompok kedua menggambarkan turunya Alqur'an secara bertahap. Ibnu Kathīr mempertegas kesimpulan ini, lagi-lagi dengan mengutip Ibnu Abbas, bahwa Alqur'an diturunkan sekaligus dari al-Lawh al-Mahfuz ke Bayt al-Izæah, kemudian diturunkan secara bertahap sesuai peristiwa-peristiwa yang terjadi selama 23 tahun $^{2}$.

Berbeda dengan Ibnu Kathīr, al-Rāzī menyebutkan dua kemungkinan jawaban atas persoalan kontradiksi dua kelompok ayat di atas. Kemungkinan pertama sama dengan jawaban yang disampaikan Ibu Kathīr. Kemungkinan kedua adalah bahwa Allah SWT. menurunkan dari al-Lawh al-Mahfuz ke langit dunia pada malam lailatul qadar sejumlah ayat Alqur'an yang akan diwahyukan kepada Rasulullah SAW. selama setahun. Pada malam lailaul qadar tahun berikutnya juga diturunkan lagi sejumlah ayat yang diperlukan untuk tahun tersebut, dan begitu seterusnya hingga purna seluruh pewahyuan Alqur'an kepada Rasulullah SAW. Menurut al-

${ }^{1}$ Abu al-Fidā` Ismā̄îl Ibnu Katsīr. Tafsìr Alqur'an al-'Aẓim (Riyadl: dār Ṭayyibah, 1999), 1:501. Ibnu Kathīr menyebutkan bahwa cerita Atiyyah diriwayatkan Ibnu Abi Hatim. Lihat, Abdurrahman bin Muhammad al-Rāzī Ibnu Abi Hatim. Tafsìr Ibnu Abiłāàtim (Riyad: Maktabah Nizar Mustafa al-Bāz, 1419 H), 1:310

${ }^{2}$ Abu al-Fidā’ Ismāōil Ibnu Katsīr. Tafsìr Alqur'an al-'Ażim (Riyadl: dār Ṭayyibah, 1999), 8:441 
Rāzī kedua jawaban memiliki probabilitas kebenaran yang sama. Sebab, kata "bulan Ramadan" pada al-Baqarah: 185 bisa berarti bulan Ramadan pada tahun tertentu, dan bisa pula bulan Ramadan tanpa ketentuan tahun. Jika arti pertama yang digunakan, maka penurunan Alqur'an dari al-Lawn al-Mahfuz ke langit dunia hanya terjadi sekali. Sebaliknya, jika arti kedua yang digunakan maka penurunan Alqur'an bisa terjadi beberapa kali, pada beberapa kali bulan Ramadan di tahun yang berbeda. Penjelasan al-Rāzī berakhir tanpa ada pilihan, mana di antara kedua jawaban yang diunggulkan ${ }^{3}$.

Al-Māwardī memunculkan jawaban ketiga. Ia mengatakan bahwa berdasarkan periwayatan Ibnu Abbas, Alqur'an diturunkan sekaligus dari al-Lawh al-Mahfuz ke langit dunia kepada malaikat safarah pada malam lailatul qadar pada bulan Ramadhan. Dari malaikat safarah ditransmisikan kepada Jibril secara bertahap dalam kurun waktu 20 (dua puluh) hari. Kemudian Jibril mewahyukannya kepada Rasulullah SAW secara bertahap dalam kurun waktu 20 tahun ${ }^{4}$.

Jawaban kedua seperti dituturkan al-Rāzī sudah pernah diungkapkan oleh Ibnu al-Anbārī jauh sebelumnya. Tetapi menurut Ibnu Hajar, apa yang disampaikan Ibnu al-Anbārī lemah, karena diceritakan melalui jalur periwayatan yang lemah dan terputus. Demikian juga pendapat alMāwardī lemah, karena diriwayatkan melalui jalur tunggal (gharīb). Ibnu Hajar memilih pendapat pertama, seperti yang disampaikan Ibnu Kathīr di atas, sebab pendapat ini didukung Hadith dengan jalur periwayatan yang beragam dan semuanya sahih ${ }^{5}$.

${ }^{3}$ Muhammad bin Umar Fakhruddin al-Rāzī. Mafātịn al-Ghayb (Beirut: Dār Iṇyā’ al-Turāth al-'Arabī, 1420 H), 5:253.

${ }^{4}$ Ali bin Muhammad al-Māwardī. al-Nukat wa al-'Uyūn (Beirut: Dār al-Kutub al'Ilmiyyah, tth), 6:311.

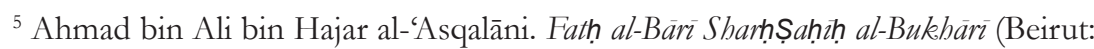
Dār al-Ma'rifah, 1379 H)., 9:4. Ibnu Hajar menyebutkan bahwa al-Nasā`̄a, Abu Ubaid dan al-Ḥakkim meriwayatkan bahwa Ibnu Abbas berkata, "Alqur'an diturunkan sekaligus ke langit dunia pada malam lailatul qadar, kemudian diturunkan (secara bertahap) selama dua puluh tahun. Lalu Ibnu Abbas membaca surat al-Isrā` ayat 106”. Di samping ketiga jalur periwayatan di atas, terdapat jalur periwayatan al-Baihaqi dan Ibnu Abi Syaibah, 
Sependapat dengan Ibnu Hajar, al-Suyūṭi mengatakan bahwa jawaban pertama adalah yang tersahih, bahkan terpopuler di kalangan ulama. Alasan yang diajukan pun sama, bahwa pendapat ini didukung Hadith dengan berbagai jalur periwayatan yang sahih ${ }^{6}$.

Persoalan pewahyuan Alqur'an dari Allah SWT hingga sampai ke Rasulullah SAW adalah hal yang tidak kasat mata. Oleh karena itu, cara yang tepat untuk mendapatkan informasi mengenai hal tersebut adalah dengan bersandar pada informasi yang sahih dari Rasulullah SAW. Itulah yang dilakukan Ibnu Kathīr, Ibnu Hajar, maupun al-Suyūṭị dalam mengungulkan jawaban pertama. Meskipun seluruh jalur periwayatan hanya berujung pada Ibnu Abbas (mawqüf) dan tidak sampai kepada Rasulullah SAW (marfü), tetapi karena materi Hadith berada di luar wilayah ijitihad, maka Hadith tersebut sama nilainya jika keluar dari Rasulullah SAW.

Berdasarkan penjelasan di atas, proses pewahyuan Alqur'an hingga sampai kepada Rasulullah SAW dapat digambarkan sebagai berikut. Allah SW'T menurunkan Alqur'an dari al-Lawh al-Mabfuz ke Bayt al-'Zzah secara utuh dan sekaligus pada bulan Ramadan, tepatnya pada malam lailatul qadar. Dari Bayt al-Izzah Alqur'an di bawa Jibril untuk disampaikan kepada Rasulullah SAW secara bertahap, sesuai dengan peristiwa-peristiwa yang dihadapinya selama kurun waktu 23 tahun.

\section{Transmisi dari Rasulullah SAW kepada Sahabat}

Selama 23 tahun masa pewahyuan, Rasulullah SAW mengajarkan dan memperdengarkan ayat yang diterima kepada para Sahabat. Imam

meskipun dengan redaksi yang sedikit berbeda. Lihat, Ahmad bin Syuaib. Al-Nasā̄, Sunan al-Kubrā (Beirut: al-Risālah, 2001), 10:205; al-Hakim Muhammad bin Abdillah alNaysābūrī. al-Mustadrak 'ala al-Ṣaḥinayn (Beirut: Dār a;-Kutub al-'Ilmiyyah, 1990), 2:399; Ahmad bin al-Husain Abu Bakar al-Bayhaqī. Daläil al-Nubuwwah (Beirut: Dār al-Kutub al-'Ilmiyyah, 1988), 7:131.

${ }^{6}$ Jalaluddin Abdurrahman bin Abu Bakar al-Suyūțy. al-Itqān fiulūm Alqur'an(1:147). Di samping menunjuk jalur periwayatan yang disebutkan Ibnu Hajar, al-Suyūṭī menambahkan jalur periwayatan al-Thabarani dengan redaksi Hadith yang sedikit berbeda. Lihat, Sulaiman bin Ahmad abu al-Qasim al-Ṭabarānī. al-Mu'jam al-Kabir (Cairo: Maktabah Ibnu Taymiyah, tth), 11:438. 
Bukhārī menceritakan bahwa Rasulullah SAW berkata kepada Ubay, "Sesungguhnya Allah memerintahkanku untuk membacakan kepadamu "

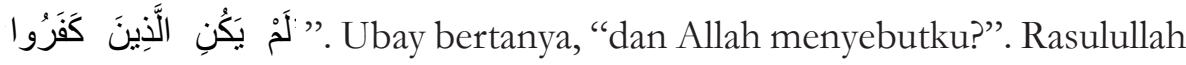
SAW menjawab, "iya”. Lalu Ubay menangis?. Ubay juga mengatakan, "aku mengambil Alqur'an dari mulut Rasulullah SAW. Karena itu aku tidak akan meninggalkannya"s.

Ibnu Mas'ud pun demikian. Ia mengatakan, "aku mengambil langsung dari mulut Rasulullah SAW 70 sekian Surah"9. Bahkan ia tahu betul pasangan surah yang dibaca dalam salat ${ }^{10}$. Ibnu Mas'ud juga menekankan pentingnya kesesuaian pembacaan dengan apa yang didengarnya dari Rasulullah SAW. Suatu saat, ia membaca surah Yusuf. Seseorang menyalahkan bacaannya dan mengatakan, "tidak seperti ini ayat itu diturunkan". Ibnu Mas'ud pun membantah, bahwa seperti inilah aku membacanya di hadapan Rasulullah SAW ${ }^{11}$.

Peristiwa yang sama juga pernah dialami Umar. Suatu saat ia mendengar Hisyam bin Hakim bin Hizam membaca surah al-Furqān dalam salat. Umar pun memperhatikan bacaan Hisyam dengan seksama. Ternyata bacaan Hisyam tidak sama dengan yang pernah dibacakan Rasulullah SAW kepada Umar. Seusai salat, Umar bertanya, "Siapakah yang mengajarkanmu bacaan Alqur'an yang aku dengar tadi?". Hisyam menjawab, "Rasulullah SAW yang mengajarkanku". "Bohong kamu", tukas Umar. "Demi Allah, Rasulullah SAW membacakan kepadaku surah ini”, bela Hisyam. Mereka berdua pun menghadap Rasulullah SAW. Ketika Umar dan Hisyam membacakan versi bacaan masing-masing, Rasulullah

${ }^{7}$ Muhammad bin Ismāìl al-Bukhāry. Șahīh al-Bukhāry (Beirut: Dār Tawq al-Najāt, 1422 H.), 6:175

${ }^{8}$ Muhammad bin Ismā'il al-Bukhāry. Șahīh al-Bukhāry (Beirut: Dār Tawq al-Najāt, 1422 H.), 6:187.

${ }^{9}$ Muhammad bin Ismā’il al-Bukhāry. Șahīh al-Bukhāry (Beirut: Dār Tawq al-Najāt, 1422 H.), 6:186.

${ }^{10}$ Muslim bin Hajjaj al-Naysābūrī, Șaḥị Muslim, (Beirut: Dār Iṇyā’ al-Turāth alArabī, tth), 1:563.

${ }^{11}$ Muhammad bin Ismā’il al-Bukhāry. Șahīh al-Bukhāry, 6:186. 
SAW membenarkan keduanya ${ }^{12}$.

Rasulullah SAW tidak hanya mengajarkan dan membacakan Alqur'an di forum khusus seperti yang dialami Ubay, Ibnu Masud, dan Umar, tetapi juga pada momentum yang lain seperti pada saat khutbah. Ummu Hisyam yang pernah berbagi dapur dengan Rasulullah SAW selama dua tahun, mengatakan bahwa ia mengambil surah qäf dari Rasulullah SAW yang selalu dibacanya dalam khutbah Jum'ah ${ }^{13}$.

Sahabat juga megambil Alqur'an dari Rasulullah SAW melalui momentum salat. Abu Hurairah misalnya, mendengar Rasulullah SAW membaca surah al-Jum'ah dan al-Munāfiqūn pada salat Jumah ${ }^{14}$. Nu'man bin Basyir memiliki pengalaman berbeda. Ia mendengar Rasulullah SAW membaca surah al- 'A’lā dan al-Ghāshiyah dalam salat Id dan salat Jumah ${ }^{15}$. Sementara Ibnu Abbas mendengar Rasulullah SAW membaca surah alSajdah dan al-Insān pada salat Subuh di hari Jumat, sedangkan pada salat Jumahnya dibaca surah al-Jum'ah dan al-Munāfiqūn ${ }^{16}$. Bahkan pernah dalam sekali salat, Rasulullah SAW membaca surah al-Baqarah, al-Nisā’ dan ‘àli 'Imrān, semuanya hinga tuntas. Hal itu dikisahkan Hudzaifah ketika suatu malam salat bersama Rasulullah SAW. ${ }^{17}$

Tidak hanya pada momentum ibadah saja, Rasulullah juga membacakan Alqur'an pada saat perjalanan. Abdullah bin Mughaffal bercerita bahwa Rasulullah SAW membaca surah al-Fath di atas Onta dalam suatu perjalanan. ${ }^{18}$

Seluruh kisah di atas hanyalah sekelumit dari keseluruhan cerita yang menggambarkan proses transmisi Alqur'an yang dilakukan Rasulullah SAW kepada para sahabatnya. Proses transmisi ini ditunjang

\footnotetext{
${ }^{12}$ Muhammad bin Ismā’il al-Bukhāry. Șahīh al-Bukhāry, 6:194.

${ }^{13}$ Muslim bin Hajjaj al-Naysābūrī, Șaḥịn Muslim, 2:595.

${ }^{14}$ Muslim bin Hajjaj al-Naysābūrī, Șaḥı̣ Muslim, 2:597.

${ }^{15}$ Muslim bin Hajjaj al-Naysābūrī, Șaḥị Muslim, 2:598.

${ }^{16}$ Muslim bin Hajjaj al-Naysābūrī, Șaḥı̣ Muslim, 2:599.

${ }^{17}$ Muslim bin Hajjaj al-Naysābūrī, Șaḥị̣ Muslim, 1:536.

${ }^{18}$ Muhammad bin Ismā’il al-Bukhāry. Șahīh al-Bukhāry, 6:195.
} 
dengan upayanya memperluas kesempatan untuk mempelajari Alqur'an kepada sebanyak-banyak orang. Rasulullah SAW pernah menikahkan dua sejoli dengan mas kawin pengajaran Alqur'an. ${ }^{19}$ Ketika seseorang datang berhijrah kepada Rasulullah SAW, ia diserahkan kepada salah satu sahabat untuk mendapatkan pelajaran Alqur'an. ${ }^{20}$

Rasulullah SAW juga memberikan motivasi agar banyak orang terdorong untuk mempelajari Alqur'an. Misalnya, Rasulullah SAW memposisikan orang yang belajar dan mengajarkan Alqur'an sebagai sebaik-baik orang. ${ }^{21}$ Di samping itu, Rasulullah SAW juga memberikan apreasi yang tinggi kepada orang-orang yang menguasai Alqur'an dengan memberikannya hak untuk menjadi imam salat. Hak ini diberikan tanpa memandang status sosialnya. Jadi, meskipun seorang budak, jika ia lebih menguasai Alqur'an dibanding yang lain, maka ia berhak menjadi imam salat. $^{22}$

Oleh karena itu tidaklah mengherankan jika banyak dari kalangan sahabat yang hafal Alqur'an. Mengutip Abu Ubaid dalam al-Qirāàt wa alQurrā', al-Suyūṭi menyebtukan bahwa penghafal Alqur'an dari kalangan muhajirin adalah Abu Bakar, Umar, Utsman, Ali, Talhah, Sa'ad, Ibnu Masud, Hudzaifah, Salim patron Abu Hudzaifah, Abu Hurairah, Abdullah bin al-Sāib, Ibnu Umar, Ibnu Abbas, Abdullah bin Amr, Ibnu Zubair, Aisyah, Hafshah, dan Ummu Salamah. Sedangkan dari kalangan ansor Ubadah bin al-Ṣāmit, Muadz bin Jabal, Mujammi’ bin Jariyah, Fuḍālah bin Ubaid, Maslamah bin Mukhallad, Ubay bin Ka'ab, Zaid bin Tsabit, Abu al-Dardā’, Anas bin Malik, dan Abu Zaid²3.

${ }^{19}$ Muhammad bin Ismā’il al-Bukhāry. Șahīh al-Bukhāry, 6:192.

${ }^{20}$ Abu Abdillah Ahmad bin Muhammad bin Hanbal. Musnad Ahmad bin Hanbal (Beirut: al-Risālah, 2001), 37:426.

${ }^{21}$ Muslim bin Hajjaj al-Naysābūrī, Șaḥịn Muslim, 2:595.

${ }^{22}$ Ibid., 1:465. Lihat pula Muhammad bin Ismā'il al-Bukhāry. Șahīh al-Bukhāry, 1:140.

${ }^{23}$ Jalaluddin Abdurrahman bin Abu Bakar al-Suyūț. al-Itqān fiulüm Alqur'an, 1:249. Lihat pula Akram Abd al-Daylamy. Jam'u Alqur'an, 28. 
Jumlah penghafal Alqur'an dari kalangan sahabat tidak terbatas pada hitungan nama-nama di atas. Pada peristiwa bi r ma'unnah 70 sahabat yang dikirim Rasulullah SAW semuanya meninggal, dan menurut Anas bin Malik mereka semua adalah para penghafal Alqur'an ${ }^{24}$. Pada perang yamāmah, sejumlah penghafal Alqur'an meninggal. Menurut Anas bin Malik jumlahnya mencapai 70 orang $^{25}$.

Alqur'an tidak hanya dihafal oleh para sahabat, tetapi sebagian juga ada yang menulisnya. Imam Bukhārī menceritakan bahwa Rasulullah SAW bersabada: "Panggilah Zaid dan suruhlah ia membawa papan, tinta, dan tulang - atau tulang dan tinta - kemudian Rasulullah SAW bersabda, “tulislah [ لا يَسْنَِّي القَاعِدُونَ ] Ketika Zaid bin Thābit menjalankan tugas untuk membukukan Alqur'an sebagaimana diperintahkan Abu Bakar, ia menghimpun catatan-catatan Alqur'an dari pelepah kurma, batu, tulang, dan dari hafalan orang-orang ${ }^{27}$. Zaid juga menuturkan bahwa para sahabat telah menyusun Alqur'an ( $t a^{\prime}(i j)$ di hadapan Rasulullah SAW yang dituliskan pada kulit ${ }^{28}$.

Dari penjelasan di atas dapat disimpulkan bahwa Alqur'an yang diwahyukan kepada Rasulullah SAW telah ditransmisikan ke generasi sahabat melalui berbagai forum dan dengan berbagai cara. Sejumlah besar sahabat merekam seluruh ayat Alqur'an dalam bentuk hafalan; sebagian lain ada yang merekam sebagian saja dari Alqur'an; dan sebagian lain merekamnya dalam bentuk tulisan.

\section{Kodifikasi Alqur’an}

Seusai perang Yamamah, Umar mengusulkan agar dilakukan penghimpunan Alqur'an. Usulan ini didasari kekhawatiran akan semakin

\footnotetext{
${ }^{24}$ Muhammad bin Ismā'il al-Bukhāry. Șahīh al-Bukhāry, 4:73.

${ }^{25}$ Muhammad bin Ismā’il al-Bukhāry. Șahīh al-Bukhāry, 5:102.

${ }^{26}$ Muhammad bin Ismā’il al-Bukhāry. Șahīh al-Bukhāry, 3:184.

${ }^{27}$ Muhammad bin Ismā'il al-Bukhāry. Șahīh al-Bukhāry, 6:71.

${ }^{28}$ Muhammad bin Isa al-Tirmidhī. Sunan al-Tirmidhì, (Cairo: Mustafa al-Bābī al-
} Halabi, 1975), 5:734. 
menyusutnya jumlah penghafal Alqur'an setelah banyak di antara mereka terbunuh. Semula Abu Bakar keberatan dengan usulan Umar. Ia beralasan bahwa penghimpunan Alqur'an tidak pernah dilakukan ataupun diperintahkan Rasulullah SAW. Tetapi Umar terus membujuk, hingga akhirnya Abu Bakar menyetujui usulannya. Abu Bakar pun memanggil Zaid bin Tsabit untuk menjalankan program ini. Awalnya, dengan alasan yang sama Zaid bin Tsabit juga keberatan atas perintah penghimpunan Alqur'an. Kini giliran Abu Bakar yang meyakinkan Zaid bin Tsabit hingga akhirnya ia bisa menerima gagasan penghimpunan Alqur'an ${ }^{29}$.

Penjelasan di atas mengimplikasikan tiga hal. Pertama, hingga Rasulullah SAW meninggal tidak ada satu mushaf pun yang menghimpun seluruh ayat Alqur'an. Penghimpunan Alqur'an dalam satu mushaf baru terjadi pada masa kekhalifahan Abu Bakar. Hal ini terlihat dari alasan penolakan Abu Bakar dan Zaid bin Tsabit atas usulan penghimpunan Alqur'an. Kedua, alasan disetujuinya gagasan penghimpunan Alqur'an adalah kekhawatiran akan musnahnya Alqur'an karena semakin menyusutnya jumlah penghafalnya. Ketiga, pelaksana program penghimpunan Alqur'an adalah Zaid bin Tsabit.

Sumber lain menyebutkan, bahwa Abu Bakar tidak hanya memberikan mandat kepada Zaid bin Tsabit, tetapi juga kepada Umar. Ibnu Abi Daud menceritakan bahwa ketika banyak penghafal Alqur'an gugur di medan perang, Abu Bakar khawatir Alqur'an akan musnah. Lalu ia memerintahkan Umar dan Zaid bin Tsabit, "duduklah kalian di pintu masjid. Jika seseorang mendatangkan kitab Allah dengan membawa dua saksi, maka catatalah"30. Dalam menjalankan perintah ini Umar tidak

${ }^{29}$ Muhammad bin Ismā'il al-Bukhāry. Șahīh al-Bukhāry, 6:71.

${ }^{30}$ Ibnu Abi Daud al-Sijistāny. al-Mașāhif (Cairo: al-Fārūq al-Hadīthah, 2002), 51. Hadith ini diceritakan Ibnu Abi Daud dari jalur Hisyam dari Urwah dari Abu Bakar. Seperti diketahui Urwah tidak pernah bertemu Abu Bakar, karena itu Hadith ini terputus sanadnya. Berdasarkan hal ini sebagian ulama berpendapat bahwa yang mendapat mandat dari Abu Bakar hanya Zaid bin Tsbait. Tetapi berdasarkan penuturan Ibnu Abi daud dari jalur yang tidak terputus, Umar turut terlibat dalam proses penghimpunan. Dialah yang mengumumkan program penghimpunan Alqur'an dan menetapkan metode dua saksi begi setiap klaim ke-Qur`an-an. Oleh karena itu, kalaupun Umar tidak mendapat 
sekedar berperan sebagai pembina yang hanya duduk di belakang meja, tetapi ia turun langsung mengumumkan siapa-siapa yang pernah menerima ayat Alqur'an dari Rasulullah SAW. Ibnu Abi Daud menceritakan, "Umar bermaksud menghimpun Alqur'an. Ia berdiri di antara orang-orang dan berkata, "Siapa yang pernah menerima Alqur'an dari Rasulullab $S A W$, maka bawalah kemari”. Sebelumnya orang-orang telah mencatat Alqur'an di lembaran, papan, dan pelepah kurma. Umar tidak bersedia menerima dari siapapun pengakuan tentang Al-quran, kecuali didukung dua saksi”"31.

Sementara perintah Abu Bakar diterjemahkan Zaid bin Tsabit dengan menulusuri naskah-naskah Alqur'an yang pernah ditulis para sahabat ataupun hafalan-hafalan yang diterima langsung dari Rasulullah SAW, hingga kemudian ia temukan dua ayat dari surah al-Tawbah pada Khuzaimah, dan tidak ditemukan pada sahabat lain ${ }^{32}$. Ibnu Hajar menjelaskan bahwa yang dimaksud "tidak ditemukan pada sahabat lain" adalah bahwa dua ayat tersebut tidak ditemukan kecuali dalam catatan Khuzaimah. Hal ini tidak menafikan bahwa sahabat lain ada yang hafal dan mendengarnya langsung dari Rasulullah SAW. Sebagaimana dikutip Ibu Hajar, Ibnu Abi Daud meriwayatkan bahwa al-Hārith bin Khuzaimah juga menyampaikan dua ayat terakhir al-Tawbah dan bahwa ia bersaksi telah mendengar kedua ayat itu dari Rasulullah SAW. Umar pun bersaksi bahwa ia juga mendengarnya dari Rasulullah $\mathrm{SAW}^{33}$.

Penjelasan di atas menggambarkan bagaimana meotde penghimpunan Alqur'an yang diterapkan pada masa Abu Bakar. Pertama, ayat Alqur'an yang dihimpun harus benar-benar diterima langsung dari Rasulullah SAW. Kedua, setiap klaim ke-Quran-an harus didukung minimal dua saksi.

mandat langsung untuk menangani penghimpunan Alqur'an, setidaknya ia terlibat atas sepengetahuan Abu Bakar.

${ }^{31}$ Ibnu Abi Daud al-Sijistāny. al-Mașāhif (Cairo: al-Fārūq al-Ḥadīthah, 2002), 62.

${ }^{32}$ Muhammad bin Ismā'il al-Bukhāry. Șahīh al-Bukhāry, 6:71.

${ }^{33}$ Ahmad bin Ali bin Hajar al-'Asqalāni. Fath al-Bārì Sharṇ Șahīh al-Bukhārì (Beirut: Dār al-Ma’rifah, 1379 H), 9:15. 
Program ini menghasilkan satu mushaf yang menghimpun seluruh ayat Alqur'an. Awalnya, mushaf tersebut berada di tangan Abu Bakar. Setelah ia meninggal, mushaf berpindah ke tangan Umar bin Khattab. Sepeninggal Umar, mushaf disimpan oleh Hafșah binti Umar.

Kodifiasi kedua terjadi pada masa kekhalifahan Utsman. Imam Bukhārī menceritakan bahwa ketika perang penaklukan Azerbeijan dan Armenia bersama umat Islam Iraq dan Syam, Hudzaifah bin al-Yaman dikagetkan oleh perbedaan mereka dalam membaca Alqur'an. Hudzaifah pun mengusulkan kepada Utsman agar segera mengatasi persoalan ini untuk menghindari terjadinya perbedaan Alqur'an seperti yang menimpa kitab suci umat Yahudi dan Nashrani ${ }^{34}$. Sebagaimana dijelaskan Ibnu Hajar, penduduk Iraq membaca Alqur'an dengan versi bacaan Ibnu Mas'ud, sedangkan penduduk Syam membacanya dengan versi bacaan Ubay bin $\mathrm{Ka}^{\prime} \mathrm{b}^{35}$.

Perbedaan bacaan Alqur'an seperti yang terjadi antara penduduk Syam dan Irak bukanlah yang pertama kali disaksikan Hudzaifah. Sebelum perang Azerbeijan Hudzaifah sudah pernah menyaksikan fenomena serupa. Ia pernah mendengar penduduk Kufah membaca Alqur'an dengan versi bacaan Ibnu Mas'ud, sedangkan orang Basrah membacanya dengan versi bacaan Abu Musa al-Asy'ari. Mendengar itu, Hudzaifah pun marah dan bermaksud melaporkannya kepada Utsman sebagai khalifah dan mengusulkan agar menyatukan pembacaan Alqur'an. Bahkan pernah suatu kali Ibnu Mas'ud mengklarifikasi ketidaksukaan Hudzaifah terhadap perbedaan versi bacaan Alqur'an. Dengan terus terang, Hudzaifah menjawab, "aku tidak suka mendengar 'versi bacaan si fulan, versi bacaan si fulan'. Kemudian hal itu akan mengakibatkan perbedaan tentang bacaan Alqur'an, seperti perselisihan Yahudi dan Nasrani atas kitab sucinya"36.

\footnotetext{
${ }^{34}$ Muhammad bin Ismā'il al-Bukhāry. Șahīh al-Bukhāry, 6:183.

${ }^{35}$ Ahmad bin Ali bin Hajar al-'Asqalāni. Fatḥ al-Bārō, 9:18.

${ }^{36}$ Ahmad bin Ali bin Hajar al-'Asqalāni. Faṭ̣ al-Bārì, 9:18.
} 
Jadi, kasus perbedaan bacaan Alqur'an yang terjadi pada perang Azerbeijan adalah pemicu yang mendorong Hudzaifah untuk segera mengusulkan penyatuan bacaan Alqur'an kepada Utsman sebagai khlaifah. Tetapi perbedaan bacaan itu sendiri sudah terjadi sebelum perang Azerbeijan.

Di sisi lain Utsman juga pernah menyaksikan sendiri kasus perbedaan pembacaan Alqur'an. Pada masa kekhalifahan Utsman, seorang pengajar Alqur'an mengajrakan bacaan versi tertentu, dan pengajar lain mengajarkannya dengan versi yang berbeda. Ketika para pelajar bertemu, mereka berbeda bacaan dan melaporkan perbedaan itu kepada masingmasing pengajarnya. Kemudian terjadilah saling mengkafirkan di antara mereka. Berita ini sampai ke telinga Utsman ${ }^{37}$. Jadi ketika Hudzaifah datang melaporkan kasus perbedaan bacaan Alqur'an, Utsman semakin yakin dengan kasus yang pernah didengarnya.

Sejatinya perbedaan pembacaan Alqur'an pernah dialami Umar dan Hisyam bin Hakim bin Hizam seperti dikemukakan di atas. Dalam kasus Umar dan Hisyam, perbedaan diselesaikan dengan mengadukannya kepada Nabi SAW. Ketika itu Rasulullah SAW membenarkan kedua versi bacaan, dan Ia bersabda, bahwa Alqur'an diturunkan atas “tujuh huruf”. Menurut al-Suyūṭi kebebasan mengucapkan Alqur'an dengan berbagai dialek adalah dispensasi pada masa awal pewahyuan, untuk memudahkan pembacaan Alqur'an bagi bangsa Arab dengan beragam dialek. Utsman berpendapat bahwa disepensasi sudah berakhir, dan karenanya diperlukan penyatuan bacaan Alqur'an untuk menghindari perpecahan dan saling mengkafirkan antar umat Islam ${ }^{38}$. Karena itulah Utsman menyetujui usulan Hudzaifah.

Kodifikasi Utsman didukung sahabat lain. Ibnu Abi Daud menceritakan, bahwa Ali berkata:

Janganlah kalian ekstrem (menilai buruk) terhadap Utsman, dan janganlah membicarakan Utsman terkait mushaf kecuali kebaikan.

${ }^{37}$ Ahmad bin Ali bin Hajar al-'Asqalāni. Fatḥ al-Bārì, 9:18.

${ }^{38}$ Jalaluddin Abdurrahman bin Abu Bakar al-Suyūṭy. al-Itqān fiulūm Alqur'an, 1: 210. 
Demi Allah ia tidak melakukan apa yang ia lakukan kecuali di hadapan banyak orang. Utsman Berkata, "apa pendapat kalian tentang pembacaan ini (perbedaan bacaan Alqur'an)? Telah sampai kepadaku bahwa sebagian di antara kalian berkata, 'bacaanku lebih baik dari bacaanmu". Ini sudah mendekati kekufuran". Kami bertanya, "lalu apa pendapatmu?". Ia menjawab, "aku berpendapat agar orangorang dipersepakatkan dalam satu mushaf, hingga tidak ada lagi perpecahan dan perbedaan". Kami menjawab, "itulah sebaik-baik pendapat"... Demi Allah seandaianya aku yang menjadi pemimpin akupun akan melakukan hal sama dengan yang dilakukannya. ${ }^{39}$

Dengan demikian kodifikasi Alqur'an yang digagas Utsman telah disampaikan dan disetujui oleh banyak sahabat.

Dari penjelasan di atas, kodifikasi kedua pada masa pemerintahan Utsman dapat dijelaskan secara kronologis sebagai berikut. Hudzaifah menyaksikan fenomena perbedaan bacaan Alqur'an antar umat Islam di Iraq. Fenomena yang sama juga disaksikan antar umat Islam di Syam dan Iraq. Hal ini menimbulkan keprihatinan dan kekhawatiran Hudzaifah akan terjadinya perbedaan Alqur'an seperti perbedaan kitab suci yang menimpa umat Yahudi dan Nasrani. Hudzaifah pun melaporkan kejadian ini kepada Utsman selaku khalifah, dan mengusulkan agar dilakukan penyatuan mushaf. Utsman sendiri juga menyaksikan fenomena yang sama. Ia pun menyetujui usulan Hudzaifah. Sebelum rencana ini dilaksanakan, Utsman menyampaikan gagasan penyatuan Alqur'an kepada para sahabat. Merekapun sepakat dengan penyatuan Alqur'an yang digagas Utsman.

Untuk menindaklanjuti gagasan tersebut, Utsman meminjam mushaf yang pernah disusun pada masa Abu Bakar dari Hafshah. Kemudian Utsman memerintahkan Zaid bin Tsabit, Abdullah Bin Zubair, Sa'ad bin al-'Āṣ dan Abdurrahman bin al-Hārith untuk menyalin Mushaf Abu Bakar ke dalam beberapa mushaf. Dari keempat orang yang menerima mandat dari Utsman, tiga di antaranya berasal dari suku Quraisy, yaitu selain Zaid bin Tsabit. Utsman berpesan kepada tiga orang yang berasal dari suku Quraisy, “jika kalian berbeda dengan Zaid bin Tsabit tentang (penulisan) Alqur’an,

\footnotetext{
${ }^{39}$ Ibnu Abi Daud al-Sijistāny. al-Mașāhif, 96.
} 
maka tulislah dengan dialek (lisān) Quraisy. Sebab Alqur'an diturunkan dengan dialek mereka"40.

Penjelasan di atas mengimplikasikan dua hal. Pertama, mushaf yang ditulis Uthman tidak sama persis dengan mushaf Abu Bakar. Sebab, jika kodifikasi kedua pada masa Uthman hanya sekedar menyalin dari mushaf Abu Bakar, tentu tidak akan ada perbedaan penulisan. Fakta ini dikuatkan dengan komentar Ibnu Syihab al-Zuhri, sebagaimana diriwayatkan Ibnu Abi Daud, bahwa pada saat itu terjadi perbedaan antara kelompok Qurays dengan Zaid bin Tsbait tentang penulisan al-tabüt ${ }^{41}$. Kelompok Qurays berpendapat, ditulis al-tabüt sedangkan Zaid berpendapat, ditulis altabūh. Lalu disampaikanlah perbedaan itu kepada Utsman. Utsman pun memerintahkan agar ditulis al-tabüt seperti dialek Qurays. Masih menurut riwayat Ibnu Abi Daud bahwa Zaid bin Tsabit merasa yakin pernah mendengar al-Aḥzāb ayat 23 dari Rasulullah SAW tetapi belum tercatat di dalam mushaf. Lalu ia menemukannya pada Abu Khuzaimah. Kedua hal ini memperkuat fakta bahwa mushaf Utsman tidak sama persis dengan mushaf Abu Bakar. Sebab, jika mushaf yang ditulis pada Utsman hanya menyalin apa adanya dari mushaf Abu Bakar, tentu Zaid bin Tsabit tidak perlu merasa ada yang belum tercatat dalam mushaf Uthman, yang kemudian ditemukan pada Abu Khuzaimah. Kedua, bahwa mushaf Uthmani ditulis dengan menggunakan dialek Qurays.

Dengan demikian, kodifikasi kedua yang bertujuan menyatukan bacaan Alqur'an bukan sekedar menyalin mushaf Abu Bakar sesuai aslinya, tetapi menjadikan mushaf Abu Bakar sebagai acuan utama dan melengkapinya dengan ayat-ayat yang belum tercatat dalam mushaf Abu Bakar. Di samping itu Mushaf Uthmani ditulis dengan menggunakan dialek Qurays.

${ }^{40}$ Muhammad bin Ismā'il al-Bukhāry. Șahīh al-Bukhāry, 6:183.

${ }^{41}$ Kata al-tabūt terdapat pada al-Baqarah: 248 dan Tāhā: 39. 


\section{Mushaf Paska Kodifikasi}

Seusai kodifikasi, Uthman mengirimkan mushaf-mushaf tersebut ke daerah-daerah kekuasaan Islam dan memerintahkan agar mushaf selain versi Utsman dimusnahkan ${ }^{42}$. Termasuk yang dimusnahkan adalah mushaf Abu Bakar pada masa pemerintahan Marwan bin Hakam. Ibnu Abi Daud meriwayatkan, bahwa Marwan meminta Hafsah untuk memberikan mushaf Abu Bakar yang disimpannya. Tetapi Hafsah menolaknya. Setelah Hafsah Wafat, mushaf Abu Bakar jatuh ke tangan Ibnu Umar. Marwan pun kembali mengirimkan permintaan itu kepada Ibnu Umar. Disetujuilah permintaan itu. Setelah mushaf tersebut sampai ke tangan Marwan, ia memerintahkan agar mushaf tersebut dimusnahkan ${ }^{43}$.

Perintah pemusnahan bukan tanpa perlawanan. Ibnu Mas'ud misalnya, menolak perintah pemusnahan dan menganjurkan muridmuridnya untuk menyembunyikan mushaf masing-masing agar selamat dari pemusnahan. Ibnu Abi Daud menceritakan, bahwa ketika diperintahkan untuk memusnahkan mushaf selain Uthmani, Ibnu Mas'ud merasa tidak suka. Ia katakan kepada murid-muridnya, "siapa di antara kalian yang bisa mengorupsi (yaghlul) mushaf, korupsilah. Sebab, seseorang akan datang di hari kiamat dengan membawa apa yang dikorupsinya. Aku telah membaca Alqur'an dari lisan Rasulullah SAW 70 surah, dan Zaid waktu itu masih kecil. Haruskah aku meninggalkan apa yang aku ambil dari Rsulullah SAW?". ${ }^{4}$

\footnotetext{
${ }^{42}$ Muhammad bin Ismā'il al-Bukhāry. Șahīh al-Bukhāry, 6:183.

${ }^{43}$ Ibnu Abi Daud al-Sijistāny. al-Mașāhif, 102.

${ }^{44}$ Ibnu Abi Daud al-Sijistāny. al-Mașāhif, 75. Lihat pula, Muslim bin Hajjaj alNaysābūrī, Șahịn Muslim, 4:1912. Ibnu Abi Daud membuat satu bab yang berjudul "kesetujuan Ibnu Mas’ud terhadap kodifikasi Utsman” (Bäb Riḍā̄ Abdillah Ibn Mas'üd li Jam 'Utsman) dan diletakkan persis setelah bab yang membicarakan ketidaksetujuan Ibnu Mas'ud. Lihat, Ibnu Abi Daud al-Sijistāny. al-Mașāhif, 82. Dalam bab itu hanya ada satu Hadith, dan menurut Ibnu Hajar tidak sesuai judul bab. Lihat, Ahmad bin Ali bin Hajar
} al-'Asqaāāni. Fatḥ al-Bārì, 9:49. 
Dari penjelasan di atas tampak bahwa Ibnu Mas'ud enggan memusnahkan mushaf-nya untuk kemudian beralih ke mushaf Uthmani sebagai satu-satunya pegangan umat Islam. Sebab ia meyakini bahwa mushaf yang dipegangnya benar-benar otentik dari Rasulullah SAW, dan karenanya tidak ada alasan untuk tidak berpegang pada mushaf tersebut.

Jadi, perintah pemusnahan tidak benar-benar langsung memusnahkan seluruh mushaf non-Utsmani. Bahkan tercatat, ada beberapa mushaf nonUthmani yang masih dibaca dan dipedomani hingga masa Tabi'in. Ibnu Abi Daud melaporkan, bahwa Abdurrahman bin al-Aswad (W. 99 H.) membaca:

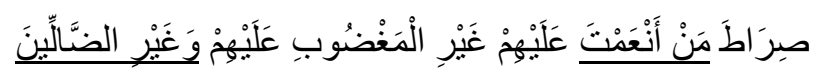

tidak seperti dalam mushaf Uthmani:

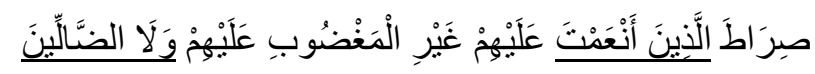

Ketika Abān bin Imrān menanyakan hal tersebut, Abdurrahman menjawab, "Ayahku menceritakan kepadaku, bahwa ia shalat di belakang Umar dan mendengarnya membaca ayat itu"45. Ibnu Abi Daud juga melaporkan adanya beberapa versi bacaan di kalangan tabiin yang tidak sama dengan versi bacaan mushaf Uthmani.

Sulaiman al-A'mash (w. 148 H.), memedomani versi bacaan Ibnu Mas'ud melalui jalur transmisi Yahya bin Waththāb dari Ubaid bin Nuḍaylah dari 'Alqamah dari Ibnu Mas'ud. Setiap bulan Sya'ban, ia membacakan Alqur'an kepada orang-orang dan di antara mereka ada pula yang membawa mushaf-nya untuk dikoreksi ${ }^{46}$. Namun demikian, hanya ada tiga nama yang tercatat memiliki jalur periwayatan mushaf Ibnu Mas'ud melalui al-A'mash, yaitu: Thalhah bin Mușarrif, Abān bin Taghlib, dan

${ }^{45}$ Ibnu Abi Daud al-Sijistāny. al-Mașāhif, 159. Kedua bacaan umar yang berbeda dari mushaf Uthmani juga dilaporkan Said bin Mansur melalui jalur isnäd yang berbeda. Lihat, Abu Uthman Said bin Mansur. al-Tafsir min sunan Sa'ìd bin Manșūr (Riyad: Dār alȘumay'î, 1997), 2: 533-534.

${ }^{46}$ Abu Abdillah Ibnu Sa'd. al-Ṭabaqāt al-Kubrā (Beirut: Dār Șādir, 1968), 6:342. 
Abu Ubaidah bin Ma'n ${ }^{47}$. Bahkan melalui al-A'mash, versi bacaan Ibnu Mas'ud masih dikenal di Kufah hingga masa Abu Hanifah ${ }^{48}$.

Namun demikian patut diyakini bahwa sejak dikeluarkannya perintah pemusnahan, peredaran mushaf Non-Uthmani terus menyusut hingga menjadi barang langka, dan akhirnya benar-benar lenyap dari peredaran. Pertanyaan Abān bin Imran kepada Abdurrahman bin Al-Aswad tentang versi bacaan Umar seperti dikemukakan di atas, mengindikasikan rasa heran Abdurrahman terhadap pembacaan mushaf non-Uthmani. Bahkan dalam diskursus Ushul Fiqih yang terekam sejak masa Abu Hanifah (w. 150 H.) versi bacaan Alqur'an non-mushaf Uthmani disebut sebagai versi bacaan yang menyimpang (shädhdhah). Oleh karena itu, meskipun alA'mash sukses mentranmisikan versi bacaan Ibnu Mas'ud, tetapi tidak cukup kuat untuk menahan arus besar mushaf Uthmani. Tiga di antara tujuh penyebar mushaf Uthmani (qiräah sab'ah) yang semasa dengan al-A'mash mengajarkan mushaf Uthmani di Kufah. Mereka adalah 'Āșim (w.127 H.), Abu 'Amr (w. 154 H.) dan Hamzah (w. 156 H.) yang juga murid Sulaiman al-A'mash. Dengan kata lain, meskipun versi bacaan Ibnu Mas'ud masih eksis di Kufah pada abad 2 H., tetapi terhitung minoritas jika dibanding pendukung mushaf Uthmani.

Pada perkembangan selanjutnya mushaf non-Uthmani sudah menjadi barang terlarang. Dalam diskursus fiqih, versi bacaan non-Uthmani tidak diperbolehkan dibaca dalam salat, ataupun dibaca sebagai Alqur'an. AlNawawi berkata, “tidak diperbolehkan membaca Alqur'an dengan versi bacaan menyimpang (shädhdhah), baik di dalam atau di luar salat. Sebab versi bacaan menyimpang bukanlah Alqur'an... Ibnu Abd al-Barr mengatakan bahwa ulama sepakat, tidak diperbolehkan membaca versi bacaan menyimpang dan tidak diperbolehkan pula berma`mum kepada orang

${ }^{47}$ Abu al-Hasan Ahmad bin Abdillah al-'jlī. Tärikeh al-Thiqāt (Madinah: Matabah al-Dār, 1985), 480.

${ }^{48}$ Ibnu Abi Sahl al-Sharakhsī. al-Mabsūṭ (Beirut: Dār al-Ma’rifah, 1993), 3:75. 
yang membaca Alqur'an versi menyimpang" ${ }^{\text {"9 }}$. Otoritas fiqih inilah yang kemudian menyeret Ibnu Shanabūdh, seorang ulama yang ahli di bidang bacaan Alqur'an, ke pengadilan pada tahun $323 \mathrm{H}$. Seluruh ulama yang dihadirkan di depan hakim, termasuk Ibnu Mujahid, sepakat menuntut pertobatan Ibnu Shanabūdh, karena telah membaca Alqur'an versi nonUthmani di dalam salat ${ }^{50}$. Sangat mungkin kisah Ibnu Shanabūdh adalah akhir dari peredaran mushaf non-Uthmani.

Versi bacaan Alqur'an non-Uthmani memang telah lenyap. Tetapi, hal itu sama sekali bukan berarti Alqur'an yang ada di tangan umat Islam sekarang ini tidak lengkap atau ada yang terkurangi. Al-Ṭabarī menjelaskan, lenyapnya versi non-Uthmani bukan karena dihapus bacaannya oleh Allah (mansükh al-tilawwah) ataupun disia-siakan oleh umat Islam. Memelihara Alqur'an adalah kewajiban. Di dalam memelihara Alqur'an, umat Islam diberikan pilihan untuk berpegang kepada salah satu di antara 7 versi bacaan (sab'at ahruf), sebagaimana orang yang melanggar sumpah diberikan pilihan untuk menebusnya dengan menjalankan salah satu dari tiga hal. Bukanlah hal yang salah seandainya seluruh umat Islam sepakat hanya menjalankan salah satu di antara tiga model tebusan, sepanjang tidak melarang model tebusan lain. Demikian halnya dengan 7 versi bacaan Alqur'an. Ia adalah pilihan dan bukan kewajiban. Sepanjang umat Islam telah memedomani salah satu dari 7 versi, dan tanpa menginkgari versi lain sebagai Alqur'an yang pernah diajarkan oleh Rasulullah SAW kepada para sahabat, maka umat Islam telah menjalankan kewajiban untuk memelihara Alqur'an ${ }^{51}$.

${ }^{49}$ Muyiddin Yahya bin Sharaf al-Nawāwī. al-Majmū' Sharḥ al-Muhadhdhab (Beirut: Dār al-Fikr, tth), 3:392.

${ }^{50}$ Syamsuddin Ibnu Khallikan. wafayāt al-A'yān wa Anbā' Abnā al-Zamān (Beirut: Dār Șādir, 1971), 4:299.

${ }^{51}$ Muhammad Ibnu Jarir al-Ṭabarī, Jāmi’ al-Bayān fi Ta wìl Alqur'an, (Beirut: alRisālah, 2000), 1:59 


\section{Penutup}

Berdasarkan uraian di atas, setidaknya bisa ditarik benang merah, untuk dapat dikatakan sebagai isi pokok dari tulisan ini. Kodifikasi Alqur'an terjadi dua kali, yaitu yang dilakukan oleh Abu Bakar dan Uthman. Kodifikasi pada masa Uthman bertujuan menyatukan bacaan Alqur'an di kalangan umat Islam. Ia tidak sekedar menyalin apa yang ada pada mushaf Abu Bakar, melainkan melengkapinya dengan ayat-ayat yang tidak terdapat pada mushaf Abu Bakar. Hal ini mengindikasikan bahwa mushaf Abu Bakar berbeda dari Mushaf Uthmani. Sementara itu, hilangnya mushaf non-Uthmani merupakan dampak kebijakan politik Uthman bin Affan. Namun demikian mushaf non-Uthmani tidak hilang seketika. Setidaknya hingga abad keempat, mushaf non-Uthmani masih dipedomani sebagian kecil umat Islam. Sedangkan terkait dengan hilangnya mushaf non-Uthmani itu tidak berarti mengurangi sedikitpun otentisitas Alqur'an yang sekarang berada di tangan umat Islam. Mushaf yang ada di tangan umat Islam sekarang ini, sama persis dengan yang diwahyukan Allah SWT kepada Rasulullah SAW melalui malaikat Jibril dengan mengacu salah satu atau lebih dari 7 versi bacaan yang dibenarkan Rasulullah SAW.

\section{Daftar Pustaka}

'Asqalāni (al), Ahmad bin Ali bin Hajar. Fatḥ al-Bārī Sharḥ Șahịh al-Bukhārì. Beirut: Dār al-Ma’rifah, 1379 H.

Bayhaqī (al), Ahmad bin al-Husain Abu Bakar. Daläil al-Nubumwah. Beirut: Dār al-Kutub al-'Ilmiyyah, 1988.

Bukhārī (al), Muhammad bin Ismail Abu Abdillah. Șaḥị al-Bukhārì. Beirut: Dār Tawq al-Najāh, 1422 H.

Daylamy (al) Akram Abd. Jam'u Alqur'ān, Dirāsat Tahlïliyyah li Marwìyyātihi. Beirut: dār al-Kutub al-'Ilmiyyah, 2006.

Ḥākim (al), Muhammad bin Abdillah al-Naysābūrī. al-Mustadrak 'ala al- 
Șaḥihayn. Beirut: Dār a;-Kutub al-'Tlmiyyah, 1990.

Hanbal, Abu Abdillah Ahmad bin Muhammad bin. Musnad Ahmad bin Hanbal. Beirut: al-Risālah, 2001.

Ḥātim, Abdurrahman bin Muhammad al-Rāzī Ibnu Abi. Tafsìr Ibnu Abì Hātim. Riyad: Maktabah Nizar Mustafa al-Bāz, 1419 H.

'Ijlī (al), Abu al-Hasan Ahmad bin Abdillah. Tārìkh al-Thiqät. Madinah: Matabah al-Dār, 1985.

Kathīr,Abu al-Fidā’ Ismā̄īl Ibnu.Tafsìr Alqur'ān al-'Aẓim. Riyadl: Dār Ṭayyibah, 1999.

Khallikan, Syamsuddin Ibnu. Wafayāt al-A'yān wa Anbā'Abnā al-Zamān. Beirut: Dār Șādir, 1971.

Mansur, Abu Utsman Said bin. al-Tafsìr min sunan Sa'ùd bin Manșūr. Riyad: Dār al-Șumay’̄î, 1997.

Māwardī (al), Ali bin Muhammad. al-Nukat wa al-'Uyūn. Beirut: Dār alKutub al-'Ilmiyyah, tth.

Nasāī (al), Ahmad bin Syuaib. Sunan al-Kubrā. Beirut: al-Risālah, 2001.

Nawāwī (al), Muyiddin Yahya bin Sharaf, al-Majmü' Sharḥ al-Muhadhdhab, Beirut: Dār al- Fikr, tth.

Naysābūrī (al), Muslim bin Hajjaj, Șaḥị̣ Muslim, Beirut: Dār Iṇyā̄alTurāth al-Arabī, tth.

Rāzì (al), Muhammad bin Umar Fakhruddin. Mafätịh al-Ghayb. Beirut: Dār Iṇyā`al-Turāth al-'Arabī, $1420 \mathrm{H}$.

Sa'd, Abu Abdillah Ibnu. al-Ṭabaqāt al-Kubrā, Beirut: Dār Șādir. 1968

Sharakhsī (al), Ibnu Abi Sahl. al-Mabsūt.t. Beirut: Dār al-Ma'rifah, 1993.

Sijistāny (al), Ibnu Abi Daud. al-Mașāhif. Cairo: al-Fārūq al-Ḥadīthah, 2002.

Suyūțī (al), Jalaluddin Abdurrahman bin Abu Bakar. al-Ashbāh wa al-Naẓäir. Beirut: Dār al-Kutub al-'Tlmiyyah, 1990.

Ṭabarānī (al), Sulaiman bin Ahmad bin Ayyub Abu al-Qāsim. Mu'jam alKabir. Cairo: Maktabah Ibnu Taimiyah, tth.

Ṭabarī (al), Muhammad Ibnu Jarir. Jämi' al-Bayān fi Ta wñl Alqur'an. Beirut: al-Risālah, 2000.

Tirmidhī (al), Muhammad bin Isa. Sunan al-Tirmidhì. Cairo: Musthafa albābī al-Hạabīin, 1975. 